\title{
Effects of Lead Time of Verbal Collision Warning Messages on Driving Behavior in Connected Vehicle Settings
}

\author{
Jingyan Wan, Changxu Wu*, Yiqi Zhang
}

Department of Industrial and System Engineering

University at Buffalo, the State University of New York, Buffalo, New York, USA 
Jingyan Wan received the B.S. degree in automation in 2007 and the M.S. degree in control science and engineering in 2009 from Harbin Institute of Techonology, Heilongjiang, China. She is currently pursuing the Ph.D. degree in industrial engineering in State University of New York at Buffalo. From 2009 to 2016, she was a Research Assistant with the Cognitive System Lab in University at Buffalo. Her research interests are driver behavior and performance in automated vehicles, in-vehicle driver assistance systems, and eco-driving systems with human in the loop.

Dr. Changxu Wu received the M.S. and the Ph.D. degrees in industrial \& operational engineering from the University of Michigan-Ann Arbor, in 2004 and 2007 respectively. He is an Associate Professor of Department of Industrial and System Engineering at the State University of New York (SUNY), Buffalo, starting from August 2007. Dr. Wu directs the Cognitive System Lab at SUNY and he is interested in integrating cognitive science and engineering system design, especially modeling human cognition system with its applications in system design, improving transportation safety, promoting human performance in human-computer interaction, and inventing innovative sustainable and smart energy systems with human in the loop. He is Associate Editors for IEEE Transactions on Intelligent Transportations Systems and Behaviour \& Information Technology. He has published more than 36 journal papers in the fields.

Yiqi Zhang received the B.S. degree in psychology from Zhejiang University, Hangzhou, China, in 2011. She is currently is currently pursuing the Ph.D. degree in industrial and system engineering at the State University of New York (SUNY), Buffalo. Her current research interest includes the development of mathematical models of human response in the interaction with engineering systems and addressing human cognition with their application in the design of the intelligent transportation systems. 


\title{
Effects of Lead Time of Verbal Collision Warning Messages on
}

\author{
Driving Behavior in Connected Vehicle Settings
}

\begin{abstract}
Introduction: Under the connected vehicle environment, vehicles will be able to exchange traffic information with roadway infrastructure and other vehicles. With such information, collision warning systems (CWSs) will be able to warn drivers with potentially hazardous situations within or out of sight and reduce collision accidents. The lead time of warning messages is a crucial factor in determining the effectiveness of CWSs in the prevention of traffic accidents. Accordingly, it is necessary to understand the effects of lead time on driving behaviors and explore the optimal lead time in various collision scenarios. Methods: The present driving simulator experiment studied the effects of controlled lead time at 16 levels (predetermined time headway from the subject vehicle to the collision location when the warning message broadcasted to a driver) on driving behaviors in various collision scenarios. Results: Maximum effectiveness of warning messages was achieved when the controlled lead time was within the range of $5 \mathrm{~s}$ to $8 \mathrm{~s}$. Specifically, the controlled lead time ranging from $4 \mathrm{~s}$ to $8 \mathrm{~s}$ led to the optimal safety benefit; and the controlled lead time ranging from $5 \mathrm{~s}$ to $8 \mathrm{~s}$ led to more gradual braking and shorter reaction time. Furthermore, a trapezoidal distribution of warning effectiveness was found by building a statistic model using curve estimation considering lead time, lifetime driving experience, and driving speed. Conclusions: The results indicated that the controlled lead time significantly affected driver performance. Practical applications: The findings have implications for the design of collision warning systems.
\end{abstract}

Keywords: Collision warning message; Lead time; Driving behavior; Driving performance; Connected Vehicles 


\section{Introduction}

Globally, deaths and injuries resulting from road traffic accidents are a major and growing public health problem. Statistically, 1.2 million people each year are known to die in road accidents worldwide, and as many as 50 million are injured (Peden et al., 2004). In 2012, 5.6 million crashes occurred in the United States, resulting in 30,800 lives lost and approximately one and a half million injuries. Almost 4 million crashes involved property damage only and it is reasonable to assume that there were many more collisions of less severity that went unreported (Highway Traffic Safety Administration, 2014).

With recent technological developments in wireless communication, mobile computing, and remote sensing, connected vehicles (CVs) be able to communicate speed and location data to roadway infrastructure and with other vehicles, and drivers can learn about the traffic situation within or out of sight (Lee \& Park, 2012; Papadimitratos, La Fortelle, Evenssen, Brignolo, \& Cosenza, 2009). With these traffic information, collision warning systems (CWSs) (Chang, Lin, Hsu, Fung, \& Hwang, 2009; Gray, 2011; Hirst \& Graham, 1997; Hoffman, Lee, \& Hayes, 2003; Isermann, Mannale, \& Schmitt, 2012; Kannan, Thangavelu, \& Kalivaradhan, 2010; J. D. Lee, McGehee, Brown, \& Reyes, 2002; Misener, 2010; Neale, Perez, Lee, \& Doerzaph, 2007; Sengupta et al., 2007; Taleb, Benslimane, \& Ben Letaief, 2010; Wada, Tsuru, Isaji, \& Kaneko, 2010) in connected vehicles are able to provide drivers with more accurate and specific traffic information, alert the driver of a potential collision within or out of sight, and promote a braking or steering response to avoid the collision or minimize the damage due to a collision.

Lead time plays an important role in determining the effectiveness of warning 
messages. Lead time was defined as the time headway from the subject vehicle to the potential collision location calculated by the collision warning system at the time the warning occurred. Existing studies suggested that early warning with longer lead time provides drivers with sufficient time to respond appropriately (Abe \& Richardson, 2004, 2005, 2006; McGehee, Brown, Wilson, \& Burns, 1998; Michon, 1993; Parasuraman, Hancock, \& Olofinboba, 1997; Seiler, Song, \& Hedrick, 1998; Tang \& Yip, 2010). Early warning also has the potential to reduce variation in braking reaction time, resulting in a more gradual and stable response. However, a warning provided too early without visual feedback may be treated as a false alarm or nuisance alarm, fail to assist the driver, and instead, generate an inappropriate braking response. This may lead a driver to no longer trust, and, therefore, ignore such warnings, thereupon impairing their effectiveness. By contrast, late warning with shorter lead time caused fewer trust issues (John Lee \& Moray, 1992; Muir, 1994; Muir \& Moray, 1996) and may not likely be ignored or forgotten. However, it leaves drivers only a short time to interpret the hazardous situation and find the appropriate response. The late warning may even disrupt an ongoing braking process. Thus, the probability of collision would be increased. A triangular distribution of general in-vehicle message usefulness has been proposed (Sohn, Lee, Bricker, \& Hoffman, 2008). The distribution indicated that the usefulness of the warning message is impaired if the warning is displayed too early or too late. Accordingly, there should be an optimal range of lead time between early and late warnings, considering the tradeoff between sufficient time to respond and trust.

There are experiments providing important insights into the effects of alert timing in emergent rear-end collision events (e.g., the lead time was shorter than 2.5s) (Abe \& Richardson, 2004, 2005, 2006; Lee et al., 2002; McGehee, Brown, Wilson, \& 
Burns, 1998) and emergent and non-emergent right-angle red-light running events at intersections (e.g., the lead time was between 2.5s and 5.5s) (Yan, Zhang, \& Ma, 2015), but other common collision scenarios remain to be studied. In the study involving red-light running events, still, the authors did not control the visual cue so that drivers might be able to perceive and respond to the impending collisions in ahead of the delivery of warning messages. Therefore, the effects of lead time may be confounded by the visual cues in those studies. A possible means of bridging this gap is to design common collision scenarios in which the driver can only rely on the warning messages to learn about and respond to the upcoming collision. Moreover, a wider range of lead times, including extreme short and long lead times, should also be investigated to study driver response in both emergent and non-emergent scenarios. This can provide a comprehensive picture of how lead time affects driving performance and thus improve the effectiveness of CWSs.

Besides lead time, researchers found that other factors might also influence the effectiveness of warning messages. Patten et al. (2006) concluded that drivers with better training and experience were able to automate driving more effectively compared with those with less driving experience in accordance with theoretical psychological models (the skill-rule-knowledge-based framework) (Rasmussen, 1987). Compared with novice drivers, experienced drivers were found to drive faster and have better performance in adjusting their driving speed appropriately when confronted with a hazard (Mueller \& Trick, 2012). Compared with experienced drivers, novice drivers had incomplete inspections of the roadway for potential hazards and were less sensitive to road complexity. When responding to emergencies, the novice drivers' speed reduction was less and their response time was longer (Cavallo \& Laurent, 1988; Deery, 2000; Markkula, Benderius, Wolff, \& Wahde, 2012; 
Mueller \& Trick, 2012; Patten, Kircher, Ostlund, Nilsson, \& Svenson, 2006; Underwood, 2007; Underwood, Chapman, Bowden, \& Crundall, 2002). Additionally, the instantaneous driving speed when the warning message sounded was found to affect driver response to the upcoming collision. According to the laws of kinematics, in order to avoid a collision or reduce the damage due to a collision, the driver with a higher speed has to brake harder than those with lower speed when confronted with the same headway or distance to the collision location. This may put more pressure on the driver and affect the driver's response process (Brown, Lee, \& McGehee, 2001; Hirst \& Graham, 1997; Lee et al., 2002).

The overall objective of this research is to investigate the effects of lead time on a driver's response to various collision scenarios with a laboratory driving experiment by controlling the effects of lifetime driving experience and driving speed. Additionally, the triangular distribution of the effectiveness of warning messages proposed by Sohn et al. (2008) will be tested with driving performance. The safety benefits of warning messages and measures of the driver response process (Lee et al., 2002) were calculated and analyzed using the experimental data to explore the optimal lead time.

\section{Methods}

\subsection{Participants}

Thirty participants (22 males, 8 females) with ages ranging from 18 to 26 years (Mean=21.07, $\mathrm{SD}=2.53)$ took part in this study. Their lifetime driving experience ranged from 1,250 to 275,000 miles (Mean=35,732, $\mathrm{SD}=60,139$ ). To be more specific, the average time since having obtained a U.S. driver's license was 4.43 years 
$(\mathrm{SD}=2.46)$ and the mean value of annual mileage was 7,833 miles $(\mathrm{SD}=6,342)$. All of them had normal or corrected-to-normal vision and reported being free of psychiatric or neurological disorders. None of the drivers had previously participated in any simulator or crash avoidance studies.

\subsection{Self-report questionnaire}

All participants were asked to complete a questionnaire before engaging in the driving task. The questionnaire was designed to collect participants' demographic information (e.g., age and gender) and driving history (e.g., annual mileage and the year a U.S. driver's license was first issued).

\subsection{Apparatus}

A STISIM® driving simulator (STISIMDRIVE M100K, Systems Technology Inc., Hawthorne, CA) was used in the study. The steering wheel was mounted to a desk. It includes a Logitech Momo® steering wheel with force feedback (Logitech Inc, Fremont, CA), a throttle pedal, and a brake pedal. The resting position of the throttle pedal is $38.2^{\circ}$ (the angle between the pedal surface and the ground) and the maximal throttle input is $15.2^{\circ}$. For the brake pedal, the resting position is $60.1^{\circ}$ and the maximal brake input is $28.6^{\circ}$. The STISIM simulator was installed on a Dell Workstation (Precision 490, Dual-Core Intel Xeon Processor 51302 GHz) with a 256 MB PCIe $\times 16$ NVIDIA graphics card, Sound Blaster® $\mathrm{X}-\mathrm{Fi}^{\mathrm{TM}}$ system, and Dell A225 Stereo System. Driving scenarios were presented on a 27 -inch LCD with $1920 \times 1200$ pixel resolution. A speaker in front of the participant provided auditory information in the form of a digitized human female voice with a speech rate of $\sim 150$ words/min and loudness level of $\sim 70 \mathrm{~dB}$. Another speaker provided driving sound effects with a 
loudness level of $\sim 55 \mathrm{~dB}$.

The behavioral measures (time elapsed (s), speed (ft/s), acceleration $\left(\mathrm{ft} / \mathrm{s}^{2}\right)$, and distance (ft)) from the driving simulator were automatically collected and outputted to another identical Dell Workstation. This computer would calculate the time to collision (TTC) in real time based on the subject vehicle's speed and acceleration at each time point. Once the calculated lead time reached the expected value (controlled lead time), the warning would occur. In addition to objective data quantifying the driver's vehicle control inputs, a video camera was used to record the driver's hands on the steering wheel and foot on the throttle and brake pedals for analysis of driving performance, reaction time, and response to collision events.

\subsection{Driving Scenarios}

The Test Block was a simulated two-lane (in each direction) urban environment with traffic lights, and road signs (e.g., stop signs) involved. There were running vehicles in each direction. Speed limit signs with a constant speed limit of $45 \mathrm{mph}$ were displayed 200 feet in front of the driver. Sixteen different collision scenarios were designed and programmed to represent the common collision events in the real world. All collision events were caused by other drivers violating the traffic regulations or exhibiting unsafe driving behaviors.

When there was a collision event, an auditory warning would sound before the appearance of the hazard vehicle. Each warning message started with a signal word "Caution" and followed by a description of the collision scenario. The signal word was used for calling driver's attention to the warning message and the upcoming collision event. The collision scenario description comprised the hazard vehicle's location and behavior, which provided the driver with specific information in order to 
reduce confusion. In order to make the warning as clear and concise as possible, the content of each warning message was determined by a focus group involving five native speakers. Three examples of collision scenarios and their corresponding warning messages were shown in Table 1.

Table 1. Three examples of collision scenarios and the corresponding warning messages.

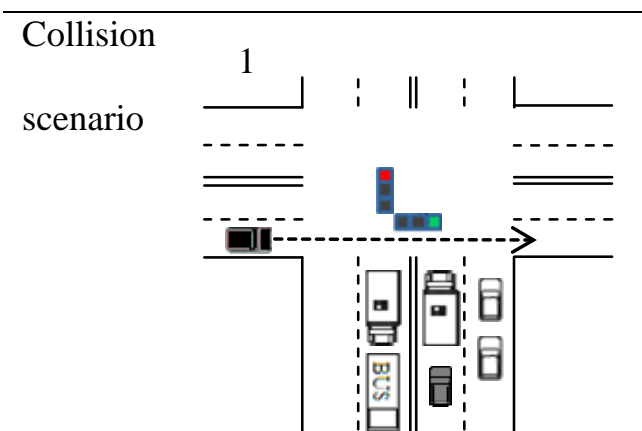

Warning Caution! A vehicle at your message front-left is running a red light
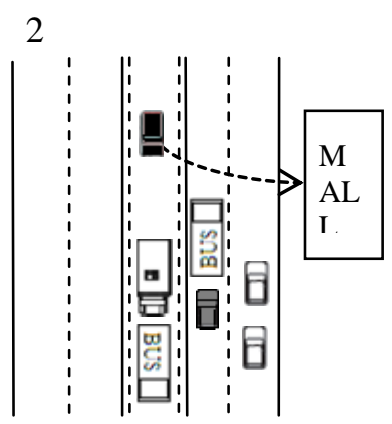

Caution! An oncoming vehicle is cutting across your lane 1000* feet ahead.

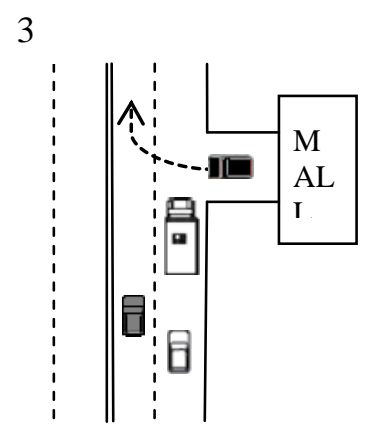

Caution! A vehicle at your front-right is cutting into your lane $1000 *$ feet ahead

Subject vehicle
ㅁI

\section{ㅁ] Other vehicles

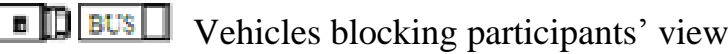

Subject vehicle's track according to the instruction in the experiment when the collision event happened at the time of making a turn.

Pre-programmed track of hazard vehicle

*Distance between the participant and hazard location was calculated on time, and the real value was presented to the participant.

\subsection{Experimental Design and Procedures}

The current experiment used the controlled lead time as the independent variable.

The controlled lead time had 16 levels $(0 \mathrm{~s}, 1 \mathrm{~s}, 1.5 \mathrm{~s}, 2 \mathrm{~s}, 2.5 \mathrm{~s}, 3 \mathrm{~s}, 3.5 \mathrm{~s}, 4 \mathrm{~s}, 4.5 \mathrm{~s}, 5 \mathrm{~s}, 6 \mathrm{~s}$, $8 \mathrm{~s}, 10 \mathrm{~s}, 15 \mathrm{~s}, 30 \mathrm{~s}$, and $60 \mathrm{~s})$. The order of the levels of lead time and collision scenarios were randomized assigned. 
We controlled two potential confounding variables in this experiment: (1) Visual Cues: If we do not control the visual cues, participants can rely on the visual cues (e.g., the appearance of a hazard vehicle) in the driving scenarios to make a response, rather than relying on the speech warning, which would confound the results. Therefore, visual cues of hazard vehicles were blocked by other vehicles and buildings in this experiment, and participants had to rely on the auditory warning messages to respond to upcoming collision events. In addition, there were no other visual cues for the participants to predict upcoming collisions in the experiment. (1) Learning Effects: (a) To address the issue of the learning effect of events, normal traffic events at 120 intersections (e.g., a stop sign with pedestrians crossing the road, a red light with a crossing vehicle at the intersection, etc.) and on 121 road segments (e.g., a horizontal curve, a parked vehicle in the parking lane, etc.) were designed and randomly assigned between two adjacent collision events. Among the 16 collision scenarios, 8 scenarios randomly appeared among the 120 intersections, and the other 8 collision scenarios randomly appeared among the 121 road segments. The distance between two adjacent collision locations was randomly assigned between 1000 feet and 10,000 feet as long as such distance can fulfill the controlled lead time of the warning (e.g., such a distance was at least 4840 feet when the controlled lead time was 60s). (b) In addition, in order to prevent drivers from anticipating collision events in association with the emergence of warning messages (i.e., to prevent them to develop a strategy in the experiment that once they hear a sound and they would press the brake pedal), there were 40 pieces of random messages not associated with any events in the driving task (e.g., weather forecast, news, etc.) with similar speech rate and loudness level of warning messages. The average numbers of words in one message were fifteen for both warnings and normal messages. 
Upon arrival, all participants were first asked to sign a consent document and then complete the self-report questionnaire. After, all participants were briefed on the operation of the simulator and completed a Practice Block that allowed them to get familiar with the driving simulator control. The scenario in the Practice Block was designed similarly with the one in the Test Block. In the 4-mile Practice Block, two randomly selected collision events (with corresponding warning messages) and five normal messages occurred. Participants were instructed to drive in the inside lane and were informed that there would be collision events with corresponding warning messages, and they should respond based on their own driving experience. They were also informed that there would be normal messages occurring during their driving.

Following the Practice Block, participants completed the Test Block comprising 16 collision events under an urban environment. Before the formal experiment, all participants were advised to adjust the seat until they felt comfortable and their feet were in full contact with the surface of the pedal. In the formal experiment, all participants were required to be observant of the traffic rules and try to keep the speed at $45 \mathrm{mph}$. If their driving speed was lower than $40 \mathrm{mph}$ or higher than $50 \mathrm{mph}$, they would be informed and advised to adjust their speed when there was no warning, turn, stop sign, or red light.

\subsection{Dependent Variables}

Behavioral measures in the driving simulator Test Block were automatically collected: time elapsed (s), speed $(\mathrm{ft} / \mathrm{s})$, acceleration $\left(\mathrm{ft} / \mathrm{s}^{2}\right)$, and distance $(\mathrm{ft})$. These experimental driving data were used to obtain the dependent variables.

Three measures described the potential safety benefit of warning messages, and three measures described the effects of the warning on the driver response (Lee et al., 
2002; Mohebbi, Gray, \& Tan, 2009; Yan et al., 2015). The potential safety benefit quantified the effectiveness of warning messages with respect to collisions, impact reduction, and collision potential. The first one was the collision, which specified whether there was a collision between a subject vehicle and a hazard vehicle. Next was the reduced kinetic energy of the subject vehicle, which specified the impact reduction led by the warning messages and was treated as the most important indicator of the effectiveness of warning messages in the current study. Because the mass of the vehicle can be different in reality, the reduced kinetic energy was calculated based on a vehicle with unit mass in the current study. The third measure was the minimum time to collision (TTC) between the emergence of the warning message and the end of the corresponding collision event. If the collision did not happen, the end of the event was defined at the time when the relative speed was zero between the subject vehicle and the hazard vehicle after the appearance of the event. If the collision happened, the end of the event was defined at the time of the collision. At this time, minimum TTC was calculated by dividing the collision velocity by the average deceleration during the whole response process and was given a negative sign. Its absolute value represented how long the time period was, before which the driver should have started braking. Minimum TTC could also be regarded as an indicator of the potential collision severity.

Three measures of the driver response process were used to reflect the effects of warning messages on driver response. The braking profile included mean deceleration and maximum deceleration from the beginning of the warning to the end of the collision event, suggesting how gradual the braking was. Alarm-to-brake-onset time, measured from the time at which the warning information releases to the time at which the driver of the test vehicle starts to brake, was used to reflect the driver's 
response time to the warning.

\subsection{Data Analysis}

A multivariate analysis of covariance (MANCOVA) was conducted using the three dependent variables (i.e., reduced kinetic energy, collision rate and minimum TTC) to describe potential safety benefits of the warning messages and three dependent variables (i.e., mean deceleration, maximum deceleration, and alarm-to-brake-onset time) to describe the driver response process, and lifetime driving experience, and initial velocity as covariates to examine the effects of controlled lead time. Initially, all analyses were conducted with the order of scenarios as between-participants factors. There were NO significant main effects or significant interactions with the order for any of the dependent measures. Neither of the interaction effects between the lead time and scenarios nor between the lead time and order were significant on any of the dependent measures (see section 3.2). Therefore, all subsequent analyses presented were collapsed across order.

Then, the statistical model of the potential safety benefits of warning messages and driver response was built using curve estimation with the independent variables of controlled lead time, lifetime driving experience, and initial velocity. Lastly, the path analysis was applied to examine the causal and correlated relationships between controlled lead time, lifetime driving experience, initial velocity, potential safety benefits of warning messages and driver response process.

\section{Results}

\subsection{Descriptive analysis}


Descriptive statistics (i.e., sample means and standard deviations) on dependent variables were provided to describe the effectiveness of warning messages (see Table 2). Collision rate was defined as the percentage of collisions for each level of lead time.

Table 2. The means and standard deviations of dependent variables

\begin{tabular}{|c|c|c|c|c|c|c|c|c|}
\hline $\begin{array}{l}\text { Controlled lead } \\
\text { time }(\mathrm{s})\end{array}$ & $\mathrm{ead}$ & 1 & 1.5 & 2 & 2.5 & 3 & 3.5 & 4 \\
\hline \multicolumn{9}{|c|}{ Safety benefits of warning messages } \\
\hline \multirow{4}{*}{$\begin{array}{l}\text { Reduced } \\
\text { kinetic } \\
\text { energy (J) } \\
\text { Collision } \\
\text { rate } \\
\text { Minimum } \\
\text { TTC (s) }\end{array}$} & \multirow{2}{*}{$\begin{array}{c}91.46 \\
(107.57)\end{array}$} & 140.38 & 220.90 & 213.16 & 312.88 & 342.56 & 371.40 & 401.24 \\
\hline & & $(129.12)$ & $(137.94)$ & $(162.82)$ & $(131.62)$ & $(104.46)$ & $(78.76)$ & $(86.33)$ \\
\hline & .96 & .93 & .80 & .72 & .53 & .36 & .23 & .17 \\
\hline & $\begin{array}{l}-116.35 \\
(198.84)\end{array}$ & $\begin{array}{l}-7.80 \\
(7.99)\end{array}$ & $\begin{array}{l}-4.10 \\
(4.54)\end{array}$ & $\begin{array}{l}-3.12 \\
(6.06)\end{array}$ & $\begin{array}{c}-.20 \\
(2.26)\end{array}$ & $\begin{array}{c}.25 \\
(3.68)\end{array}$ & $\begin{array}{c}1.12 \\
(3.40)\end{array}$ & $\begin{array}{c}2.42 \\
(2.12)\end{array}$ \\
\hline \multicolumn{9}{|c|}{ Driver response process measurements } \\
\hline \multirow{2}{*}{$\begin{array}{l}\text { Mean } \\
\text { deceleration } \\
\left(\mathrm{m} / \mathrm{s}^{2}\right)\end{array}$} & 3.38 & 2.25 & 3.08 & 2.71 & 3.37 & 3.40 & 3.11 & 3.05 \\
\hline & $(3.00)$ & $(2.11)$ & $(1.63)$ & $(1.88)$ & $(1.26)$ & $(1.17)$ & $(1.18)$ & $(.72)$ \\
\hline \multirow{2}{*}{$\begin{array}{l}\text { Maximum } \\
\text { deceleration } \\
\left(\mathrm{m} / \mathrm{s}^{2}\right)\end{array}$} & 3.76 & 4.33 & 6.19 & 5.55 & 6.25 & 6.36 & 6.34 & 6.28 \\
\hline & $(3.11)$ & $(2.77)$ & $(.33)$ & $(1.56)$ & $(.22)$ & $(.04)$ & $(.06)$ & $(.17)$ \\
\hline \multirow{2}{*}{$\begin{array}{l}\text { Warning-to-b } \\
\text { rake-onset } \\
\text { time (s) } \\
\end{array}$} & .94 & .76 & 1.01 & 1.20 & 1.15 & 1.31 & 1.36 & 1.59 \\
\hline & $(.43)$ & $(.32)$ & $(.38)$ & $(.43)$ & $(.30)$ & $(.60)$ & $(.79)$ & $(.76)$ \\
\hline \multicolumn{2}{|c|}{$\begin{array}{l}\text { Controlled lead } \\
\text { time (s) } \\
\end{array}$} & 5 & 6 & 8 & 10 & 15 & 30 & 60 \\
\hline \multicolumn{9}{|c|}{ Safety benefits of warning messages } \\
\hline \multirow{2}{*}{$\begin{array}{l}\text { Reduced } \\
\text { kinetic } \\
\text { energy (J) }\end{array}$} & \multirow{2}{*}{$\begin{array}{l}411.53 \\
(72.36)\end{array}$} & 413.14 & 413.64 & 411.74 & 388.82 & 361.35 & 385.90 & 295.48 \\
\hline & & $(46.90)$ & $(51.97)$ & $(43.30)$ & $(99.43)$ & $(108.29)$ & $(132.28)$ & $(175.42)$ \\
\hline $\begin{array}{l}\text { Collision } \\
\text { rate }\end{array}$ & .07 & .11 & .06 & .10 & .07 & .13 & .21 & .37 \\
\hline $\begin{array}{l}\text { Minimum } \\
\text { TTC (s) }\end{array}$ & $\begin{array}{c}3.10 \\
(1.11)\end{array}$ & $\begin{array}{c}3.29 \\
(1.15)\end{array}$ & $\begin{array}{c}3.84 \\
(1.11)\end{array}$ & $\begin{array}{c}3.26 \\
(1.46)\end{array}$ & $\begin{array}{l}3.39 \\
(.840)\end{array}$ & $\begin{array}{c}3.65 \\
(1.48)\end{array}$ & $\begin{array}{c}3.71 \\
(1.54)\end{array}$ & $\begin{array}{l}-27.55 \\
(55.55)\end{array}$ \\
\hline \multicolumn{9}{|c|}{ Driver response process measurements } \\
\hline \multirow{6}{*}{$\begin{array}{l}\text { Mean } \\
\text { deceleration } \\
\left(\mathrm{m} / \mathrm{s}^{2}\right) \\
\text { Maximum } \\
\text { deceleration } \\
\left(\mathrm{m} / \mathrm{s}^{2}\right) \\
\text { Warning-to } \\
\text {-brake-onse } \\
\mathrm{t} \text { time (s) }\end{array}$} & \multirow{2}{*}{$\begin{array}{c}2.69 \\
(1.06)\end{array}$} & 2.18 & 2.08 & 1.56 & 1.17 & .74 & .36 & .16 \\
\hline & & $(.81)$ & $(.72)$ & $(.36)$ & $(.42)$ & $(.25)$ & $(.12)$ & (.11) \\
\hline & 6.13 & 5.96 & 5.80 & 5.58 & 5.56 & 5.67 & 6.03 & 5.91 \\
\hline & $(.41)$ & (.61) & (.78) & (.93) & (1.24) & $(1.03)$ & $(.56)$ & $(.97)$ \\
\hline & 1.50 & 1.62 & 1.60 & 2.65 & 3.14 & 6.07 & 1.97 & 2.03 \\
\hline & $(.88)$ & $(.75)$ & $(.60)$ & (1.61) & $(2.62)$ & $(6.19)$ & $(.81)$ & $(.96)$ \\
\hline
\end{tabular}


experience, and initial velocity

The interaction effects between the lead time and scenarios were not significant on the reduced kinetic energy, collision, minimum TTC, mean deceleration, maximum deceleration, and warning-to-brake-onset time $(F(198,167)=1.199, p=.132$; $F(198,167)=1.161, p=.160 ; F(198,167)=1.216, p=.096 ; F(198,167)=.996, p=.235$ $F(198,167)=1.032, p=.201 ; F(198,167)=1.204, p=.113)$. Also, the interaction effects between the lead time and order were not significant on these dependent variables $(F(125,240)=1.663, p=.078 ; F(125,240)=.924, p=.539 ; F(125,240)=1.702, p=.051 ;$ $F(125,240)=1.520, p=.099 ; F(125,240)=1.384, p=.237 ; F(125,240)=1.487, p=.145)$.

\subsubsection{Safety benefit of warning messages: Reduced kinetic energy, collision, and} minimum TTC

Results indicated significant effects of controlled lead time $(F(15,371)=18.157$, $p=.000)$ and initial velocity $(F(1,371)=272.325, p=.000)$ on reduced kinetic energy.

It was found that early warning messages significantly reduced the potential impact compared with the late ones and that the greatest safety benefit was achieved by a lead time ranging from 4 to 8 s. As shown in Figure 1, a considerable increase in reduced kinetic energy occurred with the lead time getting longer when the warning was late. The rate of such increase tended to slow down when the warning was relatively early, and a decrease occurred when there was an extremely early warning (e.g., 60s). The Tukey multiple comparison tests showed that reduced kinetic energy was significantly lower when the controlled lead time was 0s than 2-60s; lower at $1-1.5 \mathrm{~s}$ than $2.5-30 \mathrm{~s}$; lower at $2 \mathrm{~s}$ than $4-10 \mathrm{~s}$ and $30 \mathrm{~s}$, and lower at $60 \mathrm{~s}$ than $4-8 \mathrm{~s}$. 


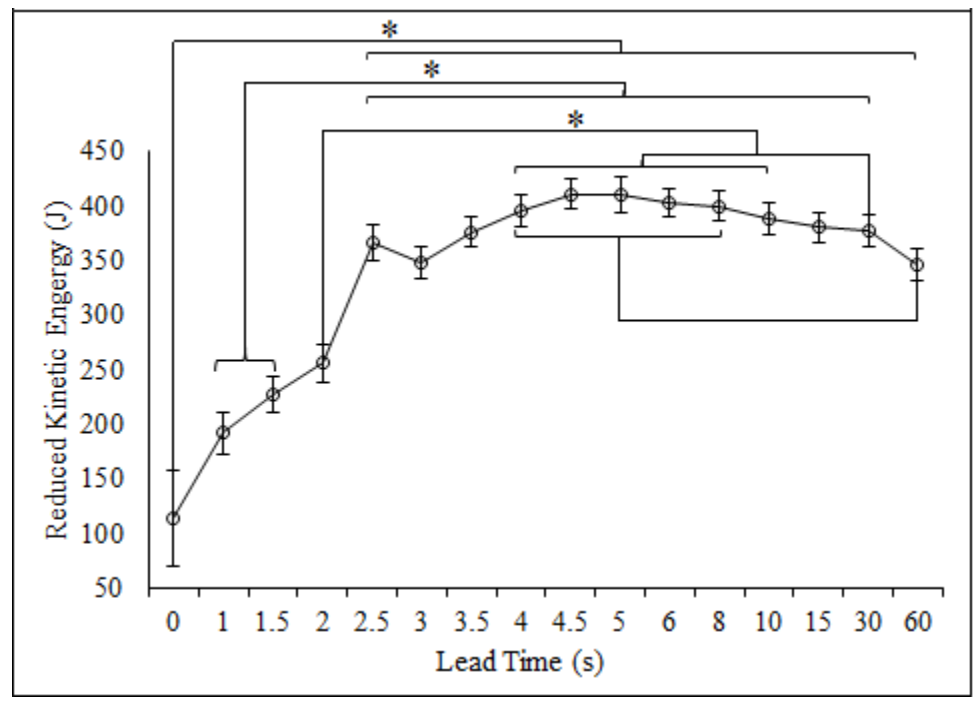

Figure 1. Effects of controlled lead time on reduced kinetic energy $\left({ }^{*} p<.05\right)$.

The significant effect of controlled lead time and initial velocity on collision rate was also observed $(F(15,371)=19.330, p=.000, F(1,371)=8.021 p=.005$, respectively $)$. Generally speaking, early warning resulted in fewer collisions than did late warning and that a lead time ranging from 4.5 to 10 s brought the greatest safety benefit. As shown in Figure 2, an abrupt decrease of collision rate appeared with the lead time getting longer when the warning was relatively late; the rate of such decrease tended to slow down when the warning was relatively early (e.g., 4.5-10s) and a slight pick-up occurred when there was an extremely early warning (e.g., 60s). The results of the Tukey multiple comparison tests showed that collision rate was significantly higher when the controlled lead time was $0 \mathrm{~s}$ rather than $3.5-30 \mathrm{~s}$; higher at $1-1.5 \mathrm{~s}$ than at $3-60 \mathrm{~s}$; and higher at $3.5 \mathrm{~s}$ than at $6 \mathrm{~s}$. 


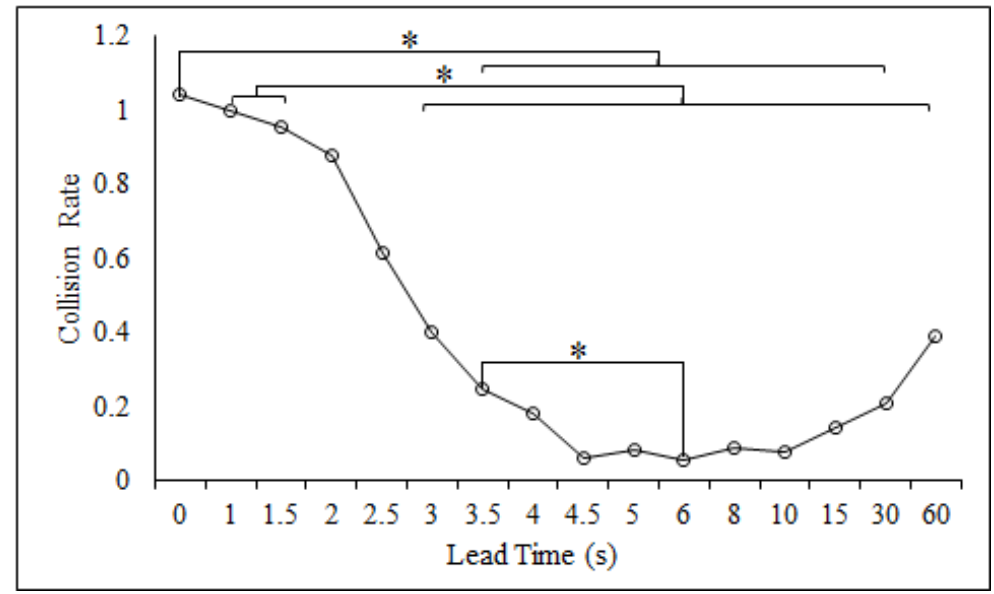

Figure 2. Effects of controlled lead time on collision rate $\left({ }^{*} p<.05\right)$.

Results indicated that there was a significant main effect of controlled lead time on minimum TTC $(F(15,371)=9.337, p=.000)$. Figure 3 showed that the minimum TTC increased sharply as the lead time grew in the beginning. The increase of the minimum TTC slowed down with the lead time getting longer and a downward trend appeared finally when the warning was too early (e.g., 60s). A Tukey multiple comparison test was performed on the minimum TTC. The results showed that the minimum TTC was significantly smaller when the controlled lead time was 0s rather than $1-30 \mathrm{~s}$, and larger at $1.5-30 \mathrm{~s}$ than at $60 \mathrm{~s}$.

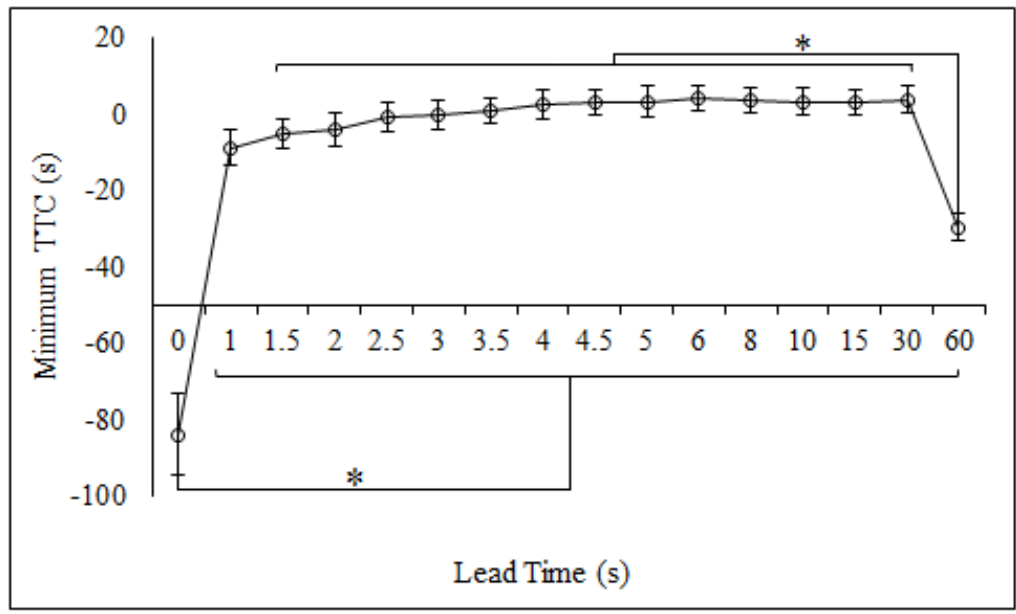

Figure 3. Effects of controlled lead time on minimum TTC $\left({ }^{*} p<.05\right)$. 
All in all, it was found that greatest safety benefits of warning messages were achieved when the controlled lead time was between $4 \mathrm{~s}$ and $8 \mathrm{~s}$ when considering the above results on reduced kinetic energy, collision rate, and minimum TTC.

\subsubsection{Driver response process: Mean deceleration, maximum deceleration, and} warning-to-brake-onset time

The main effects of controlled lead time, collision scenario, and initial velocity on mean deceleration were significant, $F(15,371)=39.626, p=.000, F(15,371)=5.286$, $p=.022$, and $F(15,371)=6.211, p=.013$, respectively. A decrease in reduced kinetic energy occurred with the lead time getting longer. To examine pair-wise differences of the mean deceleration, Tukey's test was conducted (see Figure 4). The results showed that the mean deceleration was significantly higher when controlled lead time was 0s and $10 \mathrm{~s}$ than $60 \mathrm{~s}$; higher at $1 \mathrm{~s}$ and $4.5 \mathrm{~s}$ than $8-60 \mathrm{~s}$; higher at $1.5-2 \mathrm{~s}$ than $6-60 \mathrm{~s}$; higher at 2.5-4s than 5-60s; higher at 5-6s than 10-60s; higher at 8s than 15-60s.

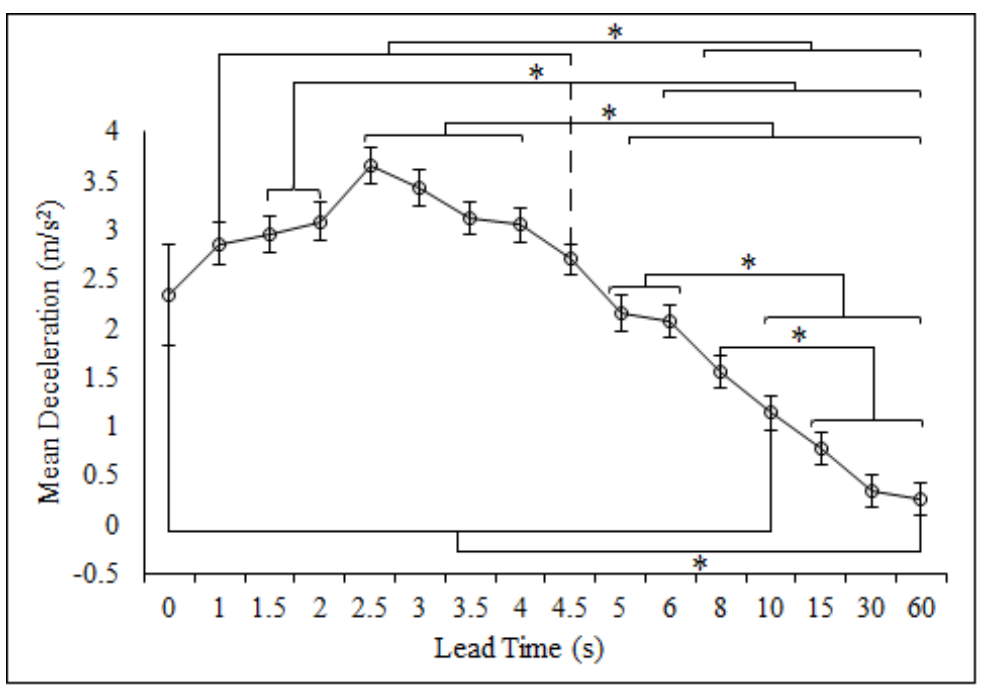

Figure 4. Effects of controlled lead time on mean deceleration $\left({ }^{*} p<.05\right)$.

The main effect of controlled lead time $(F(15,371)=3.773, p=.000)$ on maximum deceleration was significant. As shown in Figure 5, an increase in maximum 
deceleration occurred with the lead time getting longer when the warning was late. The rate of such increase tended to slow down when the warning was relatively early, and a decrease occurred when there was an early warning. Then a slight pick-up occurred when there was an extremely early warning (e.g., 30-60s). To examine pair-wise differences of the maximum deceleration, Tukey's test was conducted. The results showed that the maximum deceleration was significantly higher when controlled lead time was $1-1.5 \mathrm{~s}, 2.5-4.5 \mathrm{~s}$ and $30 \mathrm{~s}$ than $0 \mathrm{~s}$; and higher at 3-3.5s than $8-10 \mathrm{~s}$

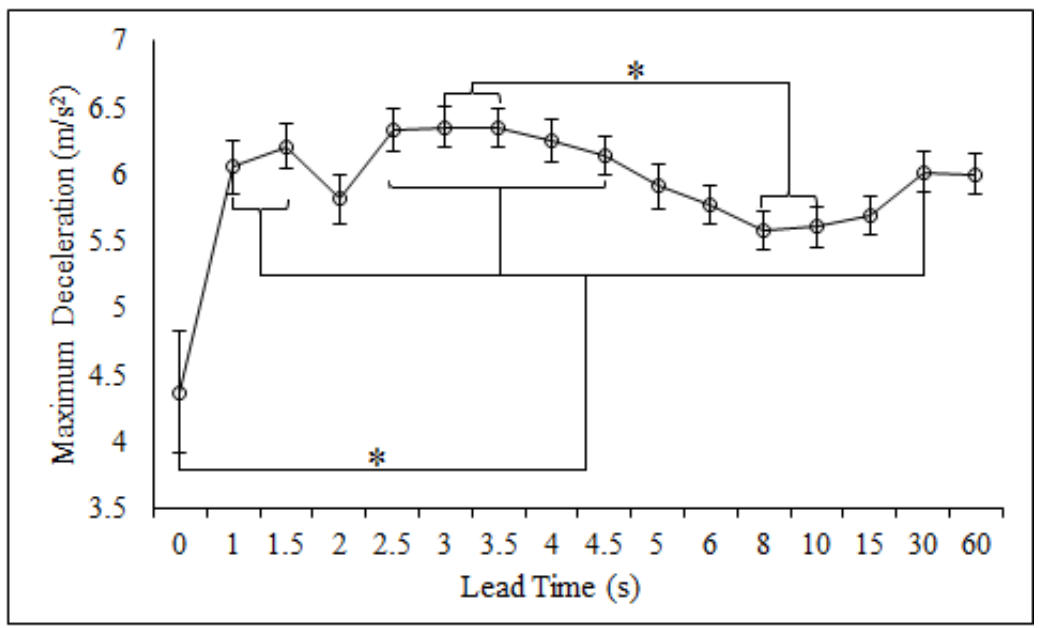

Figure 5. Effects of controlled lead time on maximum deceleration $(* p<.05)$.

The main effect of controlled lead time and initial velocity were significant on warning-to-brake-onset time $(F(15,371)=10.743, p=.000$, and $F(15,377)=14.115$, $p=.000$, respectively; see Figure 6). When the warning is early (e.g., 10s), a considerable increase in warning-to-brake-onset time occurred with the lead time getting longer. Then a decrease occurred when there was an extremely early warning (e.g., 30-60s). The Tukey multiple comparison tests showed that warning-to-brake-onset time was significantly lower when the controlled lead time was $1.5 \mathrm{~s}$ and $2.5 \mathrm{~s}$ than $10-15 \mathrm{~s}$; and lower at $1-1.5 \mathrm{~s}, 3-10 \mathrm{~s}$, and $30-60 \mathrm{~s}$ than $15 \mathrm{~s}$. 


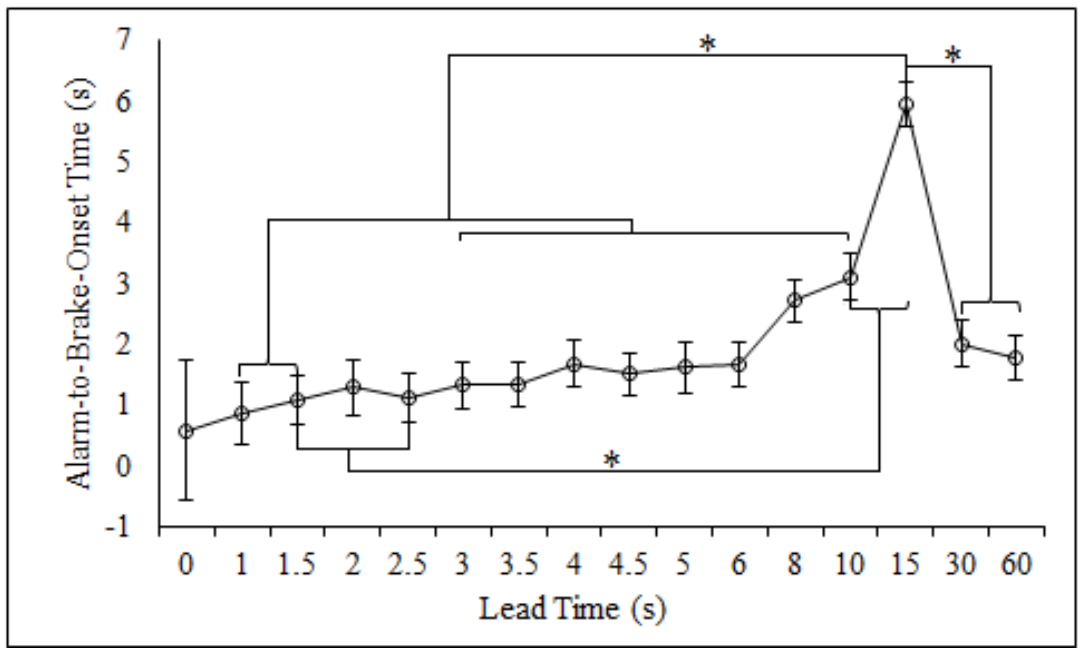

Figure 6. Effects of controlled lead time on warning-to-brake-onset time $(* p<.05)$

As suggested above, the relatively early warning messages with controlled lead time ranging from 4 s to 8 s brought in the optimal safety benefit. Specifically, such optimal safety benefit was indicated by largest kinetic energy reduction and minimum TTC, and lowest collision rate. In the meantime, a more gradual braking was illustrated when lead time increased from $5 \mathrm{~s}$ and a shorter reaction time to warning messages was obtained when controlled lead time was between 0 and $8 \mathrm{~s}$.

\subsubsection{Estimation of the potential safety benefit of warning messages and driver} response process

Based on the preceding results, the potential safety benefits of warning messages and driver response process were estimated with the relevant significant independent variables. Additionally, data were separated into different segments based on their trends to achieve better estimation. Table 3 provided the estimation results for each dependent variable, where LT, IV, and LD represented controlled lead time, initial velocity, and lifetime driving experience, respectively. Their units are second, mph, and kilo miles, respectively. 
Table 3. The summary of estimations of the potential safety benefit of warning messages and driver response process

\begin{tabular}{|c|c|c|c|}
\hline Dependent variables & Curve estimation functions & $\mathrm{R}^{2}$ & Total $\mathrm{R}^{2}$ \\
\hline Reduced kinetic & $\left\{\begin{array}{c}-5.768 \times L T^{2}+93.029 \times L T+6.591 \times I V+0.0835 \times L D-189.057 \quad(L T \leq 5 s) \\
-0.007 \times L T^{2}-1.269 \times L T+15.818 \times I V-0.0272 \times L D-302.626(L T>5 s)\end{array}\right.$ & .592 & .656 \\
\hline Collision rate & $\begin{cases}1.167-0.248 \times \mathrm{LT} & (\mathrm{LT} \leq 4.5 \mathrm{~s}) \\
0.043+0.005 \times \mathrm{LT} & (\mathrm{LT}>4.5 s)\end{cases}$ & .978 & .982 \\
\hline Minimum TTC & $\left\{\begin{array}{cc}-33.543 \times L T^{2}+127.294 \times \mathrm{LT}+1.200 \times \mathrm{IV}+0.0563 \times L D-66.159 & \mathrm{LT} \leq 2.5 \mathrm{~s} \\
0 & 2.5 \mathrm{~s}<L T \leq 15 \mathrm{~s} \\
45.380-1.069 \times \mathrm{LT} & \mathrm{LT}>15 \mathrm{~s}\end{array}\right.$ & $\begin{array}{l}.232 \\
\text { NA } \\
.092\end{array}$ & \\
\hline Mean deceleration & $\left\{\begin{array}{cl}-0.028+0.915 \times L T \quad(\mathrm{LT} \leq 2.5 \mathrm{~s}) \\
1.506-0.049 \times \mathrm{LT}+0.0232 \times \mathrm{IV} \quad(\mathrm{LT}>2.5 s)\end{array}\right.$ & .137 & \\
\hline Maximum deceleration & $\left\{\begin{array}{c}0.370+0.749 \times \mathrm{LT} \quad(\mathrm{LT} \leq 3 \mathrm{~s}) \\
1.118-0.045 \times \mathrm{LT}+0.0282 \times \mathrm{IV} \quad(\mathrm{LT}>3 s)\end{array}\right.$ & .152 & \\
\hline $\begin{array}{l}\text { Warning-to-brake-onse } \\
\text { t time }\end{array}$ & $\left\{\begin{array}{c}3.719+0.344 \times \mathrm{LT}-0.0805 \times \mathrm{IV} \quad(\mathrm{LT}<15 s) \\
0.002 \times L T^{2}-0.202 \times \mathrm{LT}-0.0407 \times \mathrm{IV}+0.00180 \times \mathrm{LD}+7.832 \quad(\mathrm{LT}>15 s)\end{array}\right.$ & .311 & \\
\hline
\end{tabular}

In a vehicle crash, the kinetic energy is suddenly transferred by crushing, tearing, and twisting the vehicle, resulting in tremendous force exerting on the vehicle's occupants that may lead to injury or even kill. By reducing the kinetic energy of a crash, the harm of the collision to the human body will be reduced. Therefore, the reduced kinetic energy was regarded as the most important indicator of the effectiveness of warning messages. The comparisons of the raw data and estimated curves of reduced kinetic energy were conducted and were shown in Table 4. Results indicated that greater reduced kinetic energy resulted from a controlled lead time of $4 \mathrm{~s}$ or longer. However, the reduced kinetic energy would decrease from the 30 s to 60 s in both conditions. 
Table 4. Comparisons between the estimated and measured reduced kinetic energy

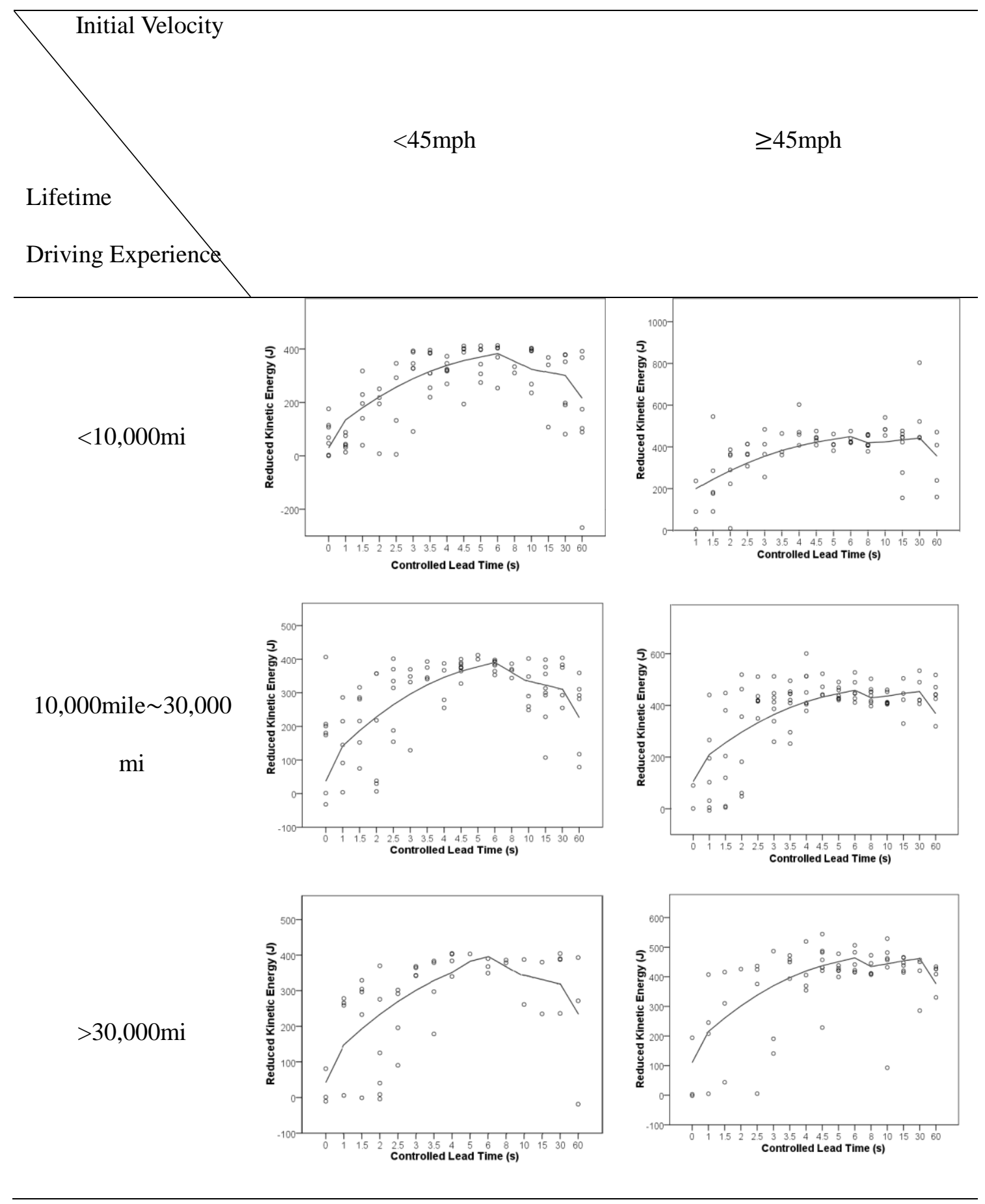

\section{Discussion}

This study investigated the effects of lead time on the effectiveness of verbal warning messages along with driving speed and lifetime driving experience under the connected vehicles (CVs) environment. Compared with previous works, the range of 
the lead time in the current study was widely extended considering the rapid development of ITSs, which enabled the researchers to study driver responses to verbal warning messages under both emergent and non-emergent collision situations. There was no visual cue of any collision events before the onset of warning, therefore, drivers had to rely only on verbal warning messages to respond to the collision events. Sixteen different collision events, rather than only rear-end collision and right-angle red-light-running collision, were designed to simulate various real life collision scenarios. Because the probability of a collision event is very low in reality, normal traffic events and non-warning messages were designed to minimize learn effect and prevent any immediate response to the onset of the message, which could help generate more realistic driver responses.

The results showed that lead time would affect the effectiveness of warning messages along with driving speed and driving experience. The maximum effectiveness of warning messages was achieved when the controlled lead time ranged from $5 \mathrm{~s}$ to $8 \mathrm{~s}$. More specifically, relatively early warning messages with controlled lead time ranging from $4 \mathrm{~s}$ to $8 \mathrm{~s}$ resulted in the optimal safety benefit, namely, maximum kinetic energy reduction and minimum TTC, and lowest collision rate. In addition, the controlled lead time ranging from 5 to 8 s led to more gradual braking responses, which was revealed by the lower mean deceleration and shorter warning-to-brake-onset time. These results showed that warnings with appropriate lead times could provide the driver with sufficient time to respond, bring less confusion or nuisance, and, therefore, lead to greater effectiveness of warning messages. Likewise, warnings in the optimal time range resulted in gradual braking, which could also reduce the risk of being struck by a following vehicle, if any.

Generally speaking, warnings given too early (e.g., the lead time was 15-60s) or 
too late the lead time was $0-2 s$ ) would undermine the effectiveness of warning messages. Warnings that were too late left the driver with almost no time to respond, which was reflected by the less safety benefit and lower deceleration. Since the length of the warning message may influence the integrity of information received by the driver in such emergent situations, the verbal message can be replaced by tones or other short stimuli, which could shorten the driver's processing time of the warning and generate an earlier response. When the warning occurred earlier (e.g., the lead time was $10-15 \mathrm{~s}$ ), the warning-to-brake-onset time was relatively longer. However, the warning-to-brake-onset time decreased when the lead time was very early (e.g., 30-60s). This suggested that too early warning could also result in unnecessary braking responses. After releasing the accelerator, most drivers were observed coasting for a long time, decelerate and accelerate with very low deceleration or acceleration for a couple of times. The most likely reason for such behaviors was that there was no visual feedback confirming the reliability of the warning, and, thereupon, the driver had to pay attention and be ready for any possible hazard when the judgment of distance was difficult. For instance, one driver crashed into a parked vehicle in the adjacent lane when looking for the hazard ahead. With very early warning (e.g., the lead time was 15-60s), 16 collisions with the hazard vehicle occurred due to drivers' uncertainty of the hazard location or treating the warning as a false alarm. Their behaviors suggested that the very early warning did not trigger drivers' braking response directly. Drivers tended to release the accelerator in the beginning and tried to prepare themselves for the potential collision event, but did not immediately depress the brake pedal until they believed themselves close enough to the hazard location or until they perceived the hazard vehicle. Any inaccurate judgment of the hazard location may trigger their improper responses. 
The statistical model of the effectiveness of warning messages was built using curve estimation. The results showed a trapezoidal distribution of the effectiveness of warning based on the changing of controlled lead time, which did not exactly follow the triangular distribution proposed by Sohn et al. (2008). Results showed that reduced kinetic energy was higher when lead time was 3-30s with the driving speed lower than $45 \mathrm{mph}$, and $4-30 \mathrm{~s}$ with the driving speed equal or higher than $45 \mathrm{mph}$. The curve tended to decline from 30 s in both conditions.

Under the CVs environment, greater safety benefits and better driving performance can be achieved by providing the CWSs with proper lead time rather than releasing the warning messages to drivers as soon as any potential collision events are detected. To be specific, when the time of headway from the driver to the collision location is shorter than $5 \mathrm{~s}$, the warning message should occur as soon as possible. When the time headway is longer than $8 \mathrm{~s}$, the onset of the warning should be postponed until the time headway reaches $8 \mathrm{~s}$. If the time headway was between $5 \mathrm{~s}$ and 8s, the warning message should also be delivered at once. CWSs designers can further apply the proposed statistical model to derive algorithms for scheduling the warning messages. Such findings can be regarded as important recommendations for the design of CWSs, which provide the effects of specific traffic situation and driver characteristics. Under the CVs environment, the effectiveness of CWSs will be enhanced by collecting driving experience information of the drivers, and by communicating with other vehicles/infrastructures on the traffic information provided by ITSs.

The limitations of the current study will be discussed below. First, gender was not balanced intentionally in the experiment. This is because no significant effect of gender on driving performance was observed in the literature involving the reaction to 
warnings during normal driving. Second, verbal messages were chosen to deliver the warning to the participants in the present study, which took time for the participant to perceive and understand. The selection of the verbal message due to its easiness in perception compared with visual messages in the peripheral field of vision. What is more, verbal messages would hardly have negative effects on a driver's visual perception in a traffic scenario, especially in emergent situations (Hollands \& Wickens, 1999). Compared with non-verbal messages, verbal messages could provide specific information of the potential hazard (e.g., reason and the location of the hazard). The present study indicated that drivers did not have sufficient time to receive the warning completely and perform response when the warning was very late (e.g., the lead time was 0-2s). In this case, non-verbal messages (e.g., tone) would be a good replacement for the verbal message implying the emergent situation, which requires much less time to perceive. Third, absence of warning or false warning messages and their influence on driver response were not investigated. The main focus of this study was on the effects of lead time on driving performance. Therefore, all warning messages given to the drivers were true warnings in this experiment. However, since drivers were unable to receive the complete warning that was provided very late (e.g., the lead time was $0-2 \mathrm{~s}$ ), such a warning can serve as an imperfect warning even if it was valid. Fourth, collision scenarios involving complex driving performance, such as lane changing and detecting hazards in the adjacent lane, were not considered in the current experiment. These behaviors were controlled to unify driver response into longitude control as much as possible in order to facilitate analysis of the results. Although most collision events designed in the experiment were forward collisions, the detailed information of the hazard (e.g., location of the collision event) was still provided rather than using the simple warning message. The 
diverse potential hazards along with corresponding messages allow those collision events to represent common collision scenarios in reality. In future studies, other types of collision scenarios besides forward collision will also be studied with specific and detailed warning messages delivering the warning information to the participant. This will also help eliminate the influence of previous exposure to similar collision events on driver's responses to subsequent events later in the experiment. Lastly, buses and trucks were used in each hazard event to block the participant's view. If an eye tracker was available to record their eye movements, it would not be necessary to block the driver's view in the experiment. To prevent the participant from predicting the hazard from the appearance of buses and trucks, these vehicles were randomly assigned in both normal and target scenarios.

Further research is needed to address other factors of warning (e.g., loudness, repetition, the rates of miss and false alarm), traffic situations (e.g., traffic density, speed limit) and participant characteristics (e.g., the level of aggressive, previous exposure to any specific collision events) on driving performance. Driver's subjective interpretations of the warning messages in different collision scenarios should also be taken into account to confirm the effectiveness of the warnings. Nevertheless, the current study constituted the first step towards a comprehensive understanding of lead time and its effect on driving performance.

\section{Acknowledgement}

We gratefully acknowledge the support by the NSF. 


\section{References}

Abe, G., \& Richardson, J. (2004). The effect of alarm timing on driver behaviour: an investigation of differences in driver trust and response to alarms according to alarm timing. Transportation Research Part F: Traffic Psychology and Behaviour, 7(4), 307-322.

Abe, G., \& Richardson, J. (2005). The influence of alarm timing on braking response and driver trust in low speed driving. Safety Science, 43(9), 639-654.

Abe, G., \& Richardson, J. (2006). Alarm timing, trust and driver expectation for forward collision warning systems. Applied Ergonomics, 37(5), 577-586.

Brown, T. L., Lee, J. D., \& McGehee, D. V. (2001). Human performance models and rear-end collision avoidance algorithms. Human Factors: The Journal of the Human Factors and Ergonomics Society, 43(3), 462-482.

Cavallo, V., \& Laurent, M. (1988). Visual information and skill level in time-to-collision estimation. Perception, 17(5), 623-632.

Chang, S.-H., Lin, C.-Y., Hsu, C.-C., Fung, C.-P., \& Hwang, J.-R. (2009). The effect of a collision warning system on the driving performance of young drivers at intersections. Transportation Research Part F: Traffic Psychology and Behaviour, 12(5), 371-380.

Deery, H. A. (2000). Hazard and risk perception among young novice drivers. Journal of Safety Research, 30(4), 225-236.

Donmez, B., Boyle, L. N., \& Lee, J. D. (2006). The impact of distraction mitigation strategies on driving performance. Human Factors: The Journal of the Human Factors and Ergonomics Society, 48(4), 785-804.

Donmez, B., Boyle, L. N., \& Lee, J. D. (2007). Safety implications of providing real-time feedback to distracted drivers. Accident Analysis \& Prevention, 39(3), 581-590.

Gray, R. (2011). Looming Auditory Collision Warnings for Driving. Human Factors: The Journal of the Human Factors and Ergonomics Society, 53(1), 63-74.

Highway Traffic Safety Administration. (2014). Traffic Safety Facts 2012. Highway Traffic Safety Administration.

Hirst, S., \& Graham, R. (1997). The format and presentation of collision warnings. Ergonomics and safety of intelligent driver interfaces, 203-219.

Hoffman, J., Lee, J. D., \& Hayes, E. M. (2003). Driver preference of collision warning strategy and modality. Paper presented at the Proceedings of the Second International Driving Symposium on Human Factors in Driver Assessment, Training and Vehicle Design.

Hollands, J. G., \& Wickens, C. D. (1999). Engineering psychology and human performance: Prentice Hall New Jersey.

Isermann, R., Mannale, R., \& Schmitt, K. (2012). Collision-avoidance systems PRORETA: Situation analysis and intervention control. Control Engineering Practice.

Joreskog, K., \& Sorbom, D. (1981). LISREL V. User's Guide. National Educational Resources. Inc, Chicago.

Kannan, S., Thangavelu, A., \& Kalivaradhan, R. B. (2010). An intelligent Driver Assistance System (I-DAS) for vehicle safety modelling using ontology approach. International Journal of UbiComp, 1(3), 15-29. 
Lee, J., \& Moray, N. (1992). Trust, control strategies and allocation of function in human-machine systems. Ergonomics, 35(10), 1243-1270.

Lee, J., \& Park, B. (2012). Development and evaluation of a cooperative vehicle intersection control algorithm under the connected vehicles environment. Intelligent Transportation Systems, IEEE Transactions on, 13(1), 81-90.

Lee, J. D., McGehee, D. V., Brown, T. L., \& Reyes, M. L. (2002). Collision warning timing, driver distraction, and driver response to imminent rear-end collisions in a high-fidelity driving simulator. Human Factors: The Journal of the Human Factors and Ergonomics Society, 44(2), 314-334.

Markkula, G., Benderius, O., Wolff, K., \& Wahde, M. (2012). Effects of experience and electronic stability control on low friction collision avoidance in a truck driving simulator. Accident Analysis \& Prevention.

McGehee, D., Brown, T., Wilson, T., \& Burns, M. (1998). Examination of driver's collision avoidance behavior in a lead vehicle stopped scenario using a front-to-rear-end collision warning system (Tech Report DTNH22-93-C-07326). USDOT/NHTSA Office of Crash Avoidance Research, Washington, DC.

McGehee, D., Brown, T., Wilson, T., \& Burns, M. (1998). Examination of drivers' collision avoidance behavior in a lead vehicle stopped scenario using a front-to-rear-end collision warning system. Contract DTNH22-93-C-07326) Washington, DC: National Highway Traffic safety Administration.

Michon, J. A. (1993). Generic intelligent driver support: CRC PressI Llc.

Misener, J. A. (2010). Cooperative Intersection Collision Avoidance System (CICAS): signalized left turn assist and traffic signal adaptation.

Mohebbi, R., Gray, R., \& Tan, H. Z. (2009). Driver reaction time to tactile and auditory rear-end collision warnings while talking on a cell phone. Human Factors: The Journal of the Human Factors and Ergonomics Society, 51(1), 102-110.

Mueller, A. S., \& Trick, L. M. (2012). Driving in fog: The effects of driving experience and visibility on speed compensation and hazard avoidance. Accident Analysis \& Prevention.

Muir, B. M. (1994). Trust in automation: Part I. Theoretical issues in the study of trust and human intervention in automated systems. Ergonomics, 37(11), 1905-1922.

Muir, B. M., \& Moray, N. (1996). Trust in automation. Part II. Experimental studies of trust and human intervention in a process control simulation. Ergonomics, 39(3), 429-460.

Neale, V. L., Perez, M. A., Lee, S. E., \& Doerzaph, Z. R. (2007). Investigation of driver-infrastructure and driver-vehicle interfaces for an intersection violation warning system. Journal of Intelligent Transportation Systems, 11(3), 133-142.

Papadimitratos, P., La Fortelle, A., Evenssen, K., Brignolo, R., \& Cosenza, S. (2009). Vehicular communication systems: Enabling technologies, applications, and future outlook on intelligent transportation. Communications Magazine, IEEE, 47(11), 84-95.

Parasuraman, R., Hancock, P., \& Olofinboba, O. (1997). Alarm effectiveness in driver-centred collision-warning systems. Ergonomics, 40(3), 390-399.

Patten, C. J. D., Kircher, A., Ostlund, J., Nilsson, L., \& Svenson, O. (2006). Driver experience and cognitive workload in different traffic environments. Accident Analysis \& Prevention, 38(5), 887-894. 
Peden, M., Scurfield, R., Sleet, D., Mohan, D., Hyder, A. A., Jarawan, E., \& Mathers, C. D. (2004). World report on road traffic injury prevention: World Health Organization Geneva.

Rasmussen, J. (1987). Cognitive control and human error mechanisms. New technology and human error, 53-61.

Seiler, P., Song, B., \& Hedrick, J. K. (1998). Development of a collision avoidance system. Development, 98, 417.

Sengupta, R., Rezaei, S., Shladover, S. E., Cody, D., Dickey, S., \& Krishnan, H. (2007). Cooperative collision warning systems: Concept definition and experimental implementation. Journal of Intelligent Transportation Systems, 11(3), 143-155.

Sohn, H., Lee, J. D., Bricker, D. L., \& Hoffman, J. D. (2008). A dynamic programming algorithm for scheduling in-vehicle messages. Intelligent Transportation Systems, IEEE Transactions on, 9(2), 226-234.

Taleb, T., Benslimane, A., \& Ben Letaief, K. (2010). Toward an effective risk-conscious and collaborative vehicular collision avoidance system. Vehicular Technology, IEEE Transactions on, 59(3), 1474-1486.

Tang, A., \& Yip, A. (2010). Collision avoidance timing analysis of DSRC-based vehicles. Accident Analysis \& Prevention, 42(1), 182-195.

Underwood, G. (2007). Visual attention and the transition from novice to advanced driver. Ergonomics, 50(8), 1235-1249.

Underwood, G., Chapman, P., Bowden, K., \& Crundall, D. (2002). Visual search while driving: skill and awareness during inspection of the scene. Transportation Research Part F: Traffic Psychology and Behaviour, 5(2), 87-97.

Wada, T., Tsuru, N., Isaji, K., \& Kaneko, H. (2010). Characterization of expert drivers' last-second braking and its application to a collision avoidance system. Intelligent Transportation Systems, IEEE Transactions on, 11(2), 413-422.

Yan, X., Zhang, Y., \& Ma, L. (2015). The influence of in-vehicle speech warning timing on drivers' collision avoidance performance at signalized intersections. Transportation Research Part C: Emerging Technologies, 51, 231-242. 
Appendix 1. Summary of the $p$-value in the results
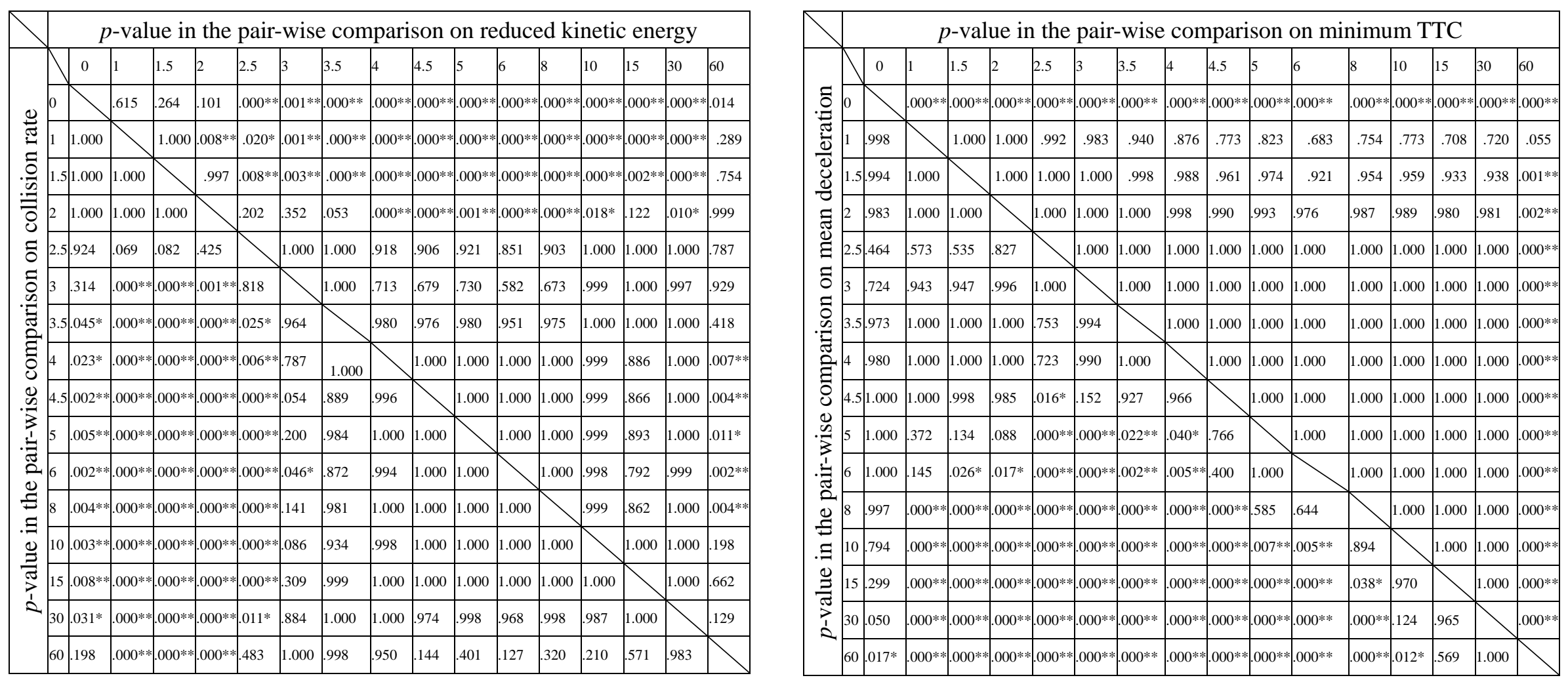


\begin{tabular}{|c|c|c|c|c|c|c|c|c|c|c|c|c|c|c|c|c|c|}
\hline & \multicolumn{17}{|c|}{$p$-value in the pair-wise comparison on maximum deceleration } \\
\hline \multirow{17}{*}{ 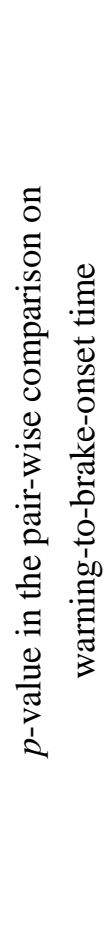 } & & 0 & 1 & 1.5 & 2 & 2.5 & 3 & 3.5 & 4 & 4.5 & 5 & 6 & 8 & 10 & 15 & 30 & 60 \\
\hline & 0 & & $.032^{\prime}$ & $.008^{* *}$ & .145 & $.004 * *$ & $.003^{* * *}$ & $.003 *$ & .006 *** & $=015$ & \begin{tabular}{|l|}
.077 \\
\end{tabular} & .140 & .360 & .342 & .246 & $.033 *$ & *. .054 \\
\hline & 1 & 1.000 & & 1.000 & 1.000 & 1.000 & 1.000 & 1.000 & 1.000 & 1.000 & 1.000 & .997 & .769 & .837 & 940 & 1.000 & 01.00 \\
\hline & 1.5 & 1.000 & 1.000 & & .943 & 1.000 & 1.000 & 1.000 & 1.000 & 1.000 & .993 & .776 & .179 & .256 & .419 & 1.000 & 0.996 \\
\hline & 2 & 1.000 & 1.000 & 1.000 & & .767 & .651 & .664 & .870 & .993 & 1.000 & 1.000 & 1.000 & 1.000 & 1.000 & 1.000 & 01.00 \\
\hline & 2.5 & 1.000 & 1.000 & $\mid$\begin{tabular}{l|l}
1.000 \\
\end{tabular} & 1.000 & & 1.000 & 1.000 & 1.000 & 1.000 & .930 & .464 & .055 & .090 & .172 & . 993 & .94 \\
\hline & 3 & 1.000 & 1.000 & 1.000 & 1.000 & 1.000 & & 1.000 & 1.000 & 1.000 & .863 & .322 & $.027^{*}$ & $.048 * *$ & .098 & .978 & .880 \\
\hline & 3.5 & 1.000 & 1.000 & 1.000 & 1.000 & 1.000 & 1.000 & & 1.000 & 1.000 & .876 & .317 & $.023^{*}$ & $.043 *$ & .091 & .983 & .892 \\
\hline & 4 & 1.000 & .996 & 1.000 & 1.000 & 1.000 & 1.000 & 1.000 & & 1.000 & \begin{tabular}{|l|}
.975 \\
\end{tabular} & .60 & .08 & 139 & .254 & .999 & .983 \\
\hline & 4.5 & 1.000 & .998 & 1.000 & 1.000 & 1.000 & 1.000 & 1.000 & 1.000 & & 1.000 & .940 & .337 & .451 & .659 & 1.000 & 01.000 \\
\hline & 5 & 1.000 & .996 & .999 & 1.000 & 1.000 & 1.000 & 1.000 & 1.000 & 1.000 & & 1.000 & .981 & .991 & .999 & 1.000 & 01.00 \\
\hline & 6 & 1.000 & & 1.000 & 1.000 & 1.000 & 1.000 & 1.000 & 1.000 & 1.000 & 1.000 & & 1.000 & 1.000 & 1.000 & . .998 & 1.00 \\
\hline & 8 & 981 & .158 & .200 & .487 & .342 & .502 & .509 & .691 & .652 & .904 & .799 & & 1.000 & 1.000 & .734 & .923 \\
\hline & 10 & .871 & $.017^{\prime}$ &. $.019 *$ & .088 & $.042 *$ & .079 & .074 & 140 & .111 & .364 & .204 & 1.000 & & 1.000 & .824 & $\begin{array}{r}4.960 \\
\end{array}$ \\
\hline & 15 & $.002 *=$ & $.000^{*}$ & $.000^{* *}$ & $.000^{* * *}$ & $.000^{* *}$ & $.000^{* *}$ & $.000 * *$ & $.000^{* *}$ & $.000 * *$ & $.000 *$ & $.000 * *$ & $.000 * *$ & $.000^{* * *}$ & & . 943 & \begin{tabular}{|l|l}
.994 \\
\end{tabular} \\
\hline & 30 & 1.000 & .863 & .947 & .995 & .987 & .998 & ..999 & 1.000 & 1.000 & 1.000 & 1.000 & .996 & .715 & $.000 *$ & & . \\
\hline & & & & & & & .995 & .997 & 1.000 & 1.000 & 1.00 & & .99 & .801 & & & \\
\hline
\end{tabular}

